\title{
The effects of smoking addiction and physical activity on some respiratory functions in female university students
}

\author{
Bilici M.F. ${ }^{1 \mathrm{ABCDE}}$, Genç A. ${ }^{2 \mathrm{ABCD}}$ \\ ${ }^{1}$ School of Physical Education and Sports, Muş AlparslanUniversity, Turkey \\ ${ }^{2}$ Faculty of Sport Science, Bartin University, Turkey
}

Authors' contributions: A - Study design; B - Data collection; C - Statistical analysis; D - Manuscript Preparation; E - Funds Collection.

\begin{abstract}
Purpose:

The aim of this study is to examine the effects of smoking addiction and physical activity on some of the respiratory functions in female university students.

Material: $\quad 103$ female students who did not have any health problems, who had an average age of 20,00 (years), average height of $163,6(\mathrm{~cm})$ and average weight of 55,88 $(\mathrm{kg})$ participated in the study voluntarily. Female students who participated in the study were grouped according to their states of having smoking addiction (athlete, sedentary) and doing exercise (athlete, sedentary) and later some of the respiratory functions were measured. SPSS program was used in the statistical analysis of the data obtained. Shapirowilk test was used to find out the normality distribution of the data. Kruskal Wallis test was used in the analysis of the data which were not normally distributed and Mann-Whitney $U$ test was used in subgroups.

Results: $\quad$ FVC(Forced Vital Capasity), FEV1(Forced Expiratory Volume in 1 second), FEV1 (Forced Expiratory Volume in 1 second )/FVC(Forced Vital Capasity), PEF(Peak Expiratory Flow), FEF25-75\% (Forced Expiratory Flow at $25-75 \%$ ), VC(Vital Capacity) and MVV(Maximal Voluntary Ventilation) values of the female students who were engaged in sports were found to be significantly higher when compared with the groups which were not engaged in sports $(p<0,05)$.

Conclusions: In addition, in terms of the variable of smoking addiction, statistically significant difference was found between the FEV1, FEV1/FVC(\%), PEF (L/s), FEF25-75\% (L/s) and MVV values of the female student groups in favour of sedentary and athlete students who were not smokers.

Keywords: respiratory functions, woman, exercise, smoking addiction, physical activity.
\end{abstract}

\section{Introduction}

Smoking has a great number of negative effects on the systems in the human organism. Respiratory system is one of the systems most affected by smoking. Smoking addiction is an important risk factor that causes hypersensitivity in the bronchi, congestion or contraction of airways and diseases such as asthma and lung cancer $[1,2]$. Diseases caused in the lungs by smoking spread from small airways to large airways [3]. Respiratory system is one of the systems that exercise and physical activity directly affect [4].

Exercise and physical activity cause the development of strength and endurance of respiratory muscles, decrease in the resistance in airways in lungs and increase in the volume and capacity of lungs and also increases the elastic properties of lungs [5]. Healthy lung capacity and strong respiratory muscles are very important for athletes [6]. Cardiorespiratory capacity is one of the important factors determining athlete performance [7]. A great number of previously conducted studies have reported that lung capacity influences athlete performance [8].

Although there are studies in the literature which have addressed the effects of smoking addiction and physical activity in adult women on respiratory capacity, there are few studies examining the effect of both factors together on respiratory functions. In the light of the data obtained from our study, we believe that a better understanding

(c) Bilici M.F., Genç A., 2020

doi:10.15561/26649837.2020.0201 of the effects of smoking addiction and physical activity simultaneously on the adult female population will contribute to increasing awareness about protection from fatal lung diseases and sportive performance.

The aim of this study is to examine the effects of smoking addiction and physical activity on some of the respiratory functions in female university students.

\section{Material and Method}

Participants. 103 female students who did not have any health problems, who had an average age of 20,00 (years), the average height of 163,6 (cm) and an average weight of 55,88 $(\mathrm{kg})$ participated in the study voluntarily. Female students who participated in the study were grouped according to their states of smoking (athlete, sedentary) and doing exercise (athlete, sedentary). Prior to the study, criteria that could affect the study were determined and the subjects who did not meet the criteria were excluded. Inclusion criteria were as follows:

- $\quad$ For the group with smoking addiction, not having any substance and alcohol addiction and having smoked at least for three years,

- For the group doing exercise, having a sport age of at least two years or more and doing sport regularly at least for an hour a day for five days a week.

\section{SpirometricMeasurements}

Respiratory function values of the female students who participated in the study were found by using a spirometer (Pony Fx, Italy). Before conducting the test, the subjects 
were informed about the rules to follow (not having a heavy meal two hours before the test, not smoking an hour before the test, not drinking alcohol 4 hours before the test, not doing intense exercise 30 minutes before the test, not wearing clothes that can tighten the rib cage, not using bronchodilator, etc.) and the procedure for a healthy measurement. After getting the voluntary consents of the participants, 10879717-050.01.04 numbered and 06/11/2019 dated ethical board approval report was taken from MuşAlpaslan University Ethical Board.

All of the measurements were made when the students were in sitting position. The tests were conducted after the students were adjusted by making them aspirate a few times with a mouthpiece attached to a spirometer while their noses were closed with a latch. The measurements were repeated three times and the best value was recorded.

Statistical Analysis.

SPSS program was used in the statistical analysis of the data. Shapiro-wilk test was used to find out the normality distribution of the data. Kruskal Wallis test was used in the analysis of the data which were not normally distributed and the Mann-Whitney U test was used in subgroups.

\section{Results}

Respiratory functions can differ according to body composition and anthropometric measurements [9]. When Table 1 is reviewed, it can be seen that the groups show a homogeneous distribution.

When Table 2 is examined, it can be seen that FVC, FEV1, FEV1/FVC(\%), PEF (L/s), FEF25-75\% (L/s), $\mathrm{VC}$ and MVV values of female athlete groups were significantly higher when compared with sedentary groups $(p<0,05)$. In addition, a statistically significant difference was found in favor of non-smoking sedentary and athlete groups between FEV1, FEV1/FVC(\%), PEF (L/s), FEF25-75\% (L/s) and MVV values of female student groups in terms of smoking addiction.

Table 1. BMI values of female university students

\begin{tabular}{|c|c|c|c|c|c|c|c|c|c|}
\hline Parameters & Group & & $\mathbf{N}$ & Ave. & S.D. & $\begin{array}{l}\text { Rank } \\
\text { Mean }\end{array}$ & $\begin{array}{l}\text { Chi- } \\
\text { Square }\end{array}$ & $\mathbf{P}$ & Significance \\
\hline & 1 & Athlete & 25 & 20.15 & 1.54 & 47.84 & & & \\
\hline & 2 & Athlete, smoking addict & 26 & 21.30 & 3.40 & 54.79 & & & \\
\hline \multirow[t]{3}{*}{ BMI $\left(\mathrm{kg} / \mathrm{m}^{2}\right)$} & 3 & Non-athlete & 27 & 20.99 & 2.18 & 55.80 & 1.374 & 0.712 & $p>0,05$ \\
\hline & 4 & Non-athlete, smoking addict & 25 & 20.96 & 3.51 & 49.16 & & & \\
\hline & & Total & 103 & 20.86 & 2.77 & & & & \\
\hline
\end{tabular}

Table 2. Respiratory function analyses of female university students

\begin{tabular}{|c|c|c|c|c|c|c|c|c|c|}
\hline Parameters & Gr & up & $\mathbf{N}$ & Ave. & S.D. & 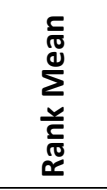 & $\begin{array}{l}\frac{0}{\frac{1}{0}} \\
\frac{0}{2} \\
\frac{0}{4} \\
\frac{1}{2} \\
\frac{5}{U}\end{array}$ & $\mathbf{P}$ & 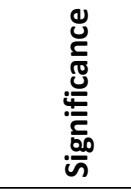 \\
\hline \multirow{5}{*}{$\mathrm{FVC}(\mathrm{L})$} & 1 & Athlete & 25 & 3.93 & 0.54 & 66.42 & \multirow{5}{*}{13.512} & \multirow{5}{*}{0,004} & \multirow{5}{*}{$\begin{array}{l}1-3 \\
1-4\end{array}$} \\
\hline & 2 & Athlete. smoking addict & 26 & 3.69 & 0.35 & 58.63 & & & \\
\hline & 3 & Non-athlete & 27 & 3.54 & 0.64 & 43.87 & & & \\
\hline & 4 & Non-athlete. smoking addict & 25 & 3.44 & 0.51 & 39.46 & & & \\
\hline & & Total & 103 & 3.65 & 0.55 & & & & \\
\hline \multirow{5}{*}{ FEV1(L) } & 1 & Athlete & 25 & 3.47 & 0.41 & 75.70 & \multirow{5}{*}{27.400} & \multirow{5}{*}{0,000} & $1-2$ \\
\hline & 2 & Athlete. smoking addict & 26 & 3.06 & 0.33 & 51.63 & & & $1-3$ \\
\hline & 3 & Non-athlete & 27 & 3.05 & 0.51 & 49.09 & & & $1-4$ \\
\hline & 4 & Non-athlete. smoking addict & 25 & 2.72 & 0.48 & 31.82 & & & $1-4$ \\
\hline & & Total & 103 & 3.08 & 0.51 & & & & $\begin{array}{l}2-4 \\
3-4\end{array}$ \\
\hline \multirow{5}{*}{$\begin{array}{l}\text { FEV1/FVC\% } \\
\text { (\%) }\end{array}$} & 1 & Athlete & 25 & 89.33 & 4.24 & 68.94 & \multirow{5}{*}{21.726} & \multirow{5}{*}{0,000} & \multirow{5}{*}{$\begin{array}{l}1-2,1-4 \\
3-4\end{array}$} \\
\hline & 2 & Athlete. smoking addict & 26 & 83.09 & 6.21 & 41.90 & & & \\
\hline & 3 & Non-athlete & 27 & 86.73 & 8.09 & 61.61 & & & \\
\hline & 4 & Non-athlete. smoking addict & 25 & 79.24 & 10.56 & 35.18 & & & \\
\hline & & Total & 103 & 84.62 & 8.42 & & & & \\
\hline \multirow{5}{*}{$\operatorname{PEF}(\mathrm{L} / \mathrm{S})$} & 1 & Athlete & 25 & 6.35 & 1.04 & 82.34 & \multirow{5}{*}{47.069} & \multirow{5}{*}{0,000} & \multirow{5}{*}{$\begin{array}{l}1-2,1-3 \\
1-4,2-4 \\
3-4\end{array}$} \\
\hline & 2 & Athlete. smoking addict & 26 & 4.55 & 1.17 & 46.35 & & & \\
\hline & 3 & Non-athlete & 27 & 4.92 & 1.13 & 54.22 & & & \\
\hline & 4 & Non-athlete. smoking addict & 25 & 3.52 & 1.07 & 25.14 & & & \\
\hline & & Total & 103 & 4.83 & 1.48 & & & & \\
\hline
\end{tabular}


Table 2 Cont.

\begin{tabular}{|c|c|c|c|c|c|c|c|c|c|}
\hline Parameters & & up & $\mathbf{N}$ & Ave. & S.D. & 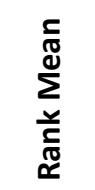 & 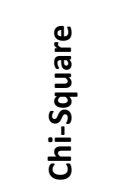 & $\mathbf{P}$ & 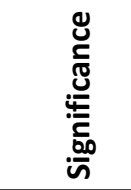 \\
\hline \multirow{5}{*}{$\begin{array}{l}\text { FEF25-75\% } \\
\text { (L/s) }\end{array}$} & 1 & Athlete & 25 & 4.26 & 0.64 & 79.60 & \multirow{5}{*}{37.914} & \multirow{5}{*}{0,000} & \multirow{5}{*}{$\begin{array}{l}1-2,1-3, \\
1-4,2-4, \\
3-4\end{array}$} \\
\hline & 2 & Athlete. smoking addict & 26 & 3.30 & 0.65 & 46.73 & & & \\
\hline & 3 & Non-athlete & 27 & 3.49 & 0.78 & 53.44 & & & \\
\hline & \multirow[t]{2}{*}{4} & Non-athlete. smoking addict & 25 & 2.80 & 0.66 & \multirow[t]{2}{*}{28.32} & & & \\
\hline & & Total & 103 & 3.46 & 0.85 & & & & \\
\hline \multirow{5}{*}{ VC (L) } & 1 & Athlete & 25 & 3.68 & 0.52 & 65.38 & \multirow{5}{*}{9.985} & \multirow{5}{*}{0,019} & \multirow{5}{*}{$1-3,1-4$} \\
\hline & 2 & Athlete. smoking addict & 26 & 3.46 & 0.33 & 56.35 & & & \\
\hline & 3 & Non-athlete & 27 & 3.34 & 0.58 & 44.69 & & & \\
\hline & \multirow[t]{2}{*}{4} & Non-athlete. smoking addict & 25 & 3.26 & 0.44 & \multirow[t]{2}{*}{42.00} & & & \\
\hline & & Total & 103 & 3.43 & 0.50 & & & & \\
\hline \multirow{5}{*}{$\mathrm{MVV}(\mathrm{L} / \mathrm{min})$} & 1 & Athlete & 25 & 96.58 & 22.73 & 67.20 & \multirow{5}{*}{26.208} & \multirow{5}{*}{0,000} & \multirow{5}{*}{$\begin{array}{l}\text { 1-4, 2-4, } \\
3-4\end{array}$} \\
\hline & 2 & Athlete. smoking addict & 26 & 87.85 & 15.79 & 55.62 & & & \\
\hline & 3 & Non-athlete & 27 & 88.84 & 16.22 & 58.07 & & & \\
\hline & 4 & Non-athlete. smoking addict & 25 & 67.56 & 15.44 & 26.48 & & & \\
\hline & & Total & 103 & 85.30 & 20.47 & & & & \\
\hline
\end{tabular}

NOTES. Parameters: FVC(L) - Forced Vital Capasity; FEV1(L)- Forced Expiratory Volume in 1 second; FEV1/FVC (\%)-Forced; Expiratory Volume in 1 second )/Forced Vital Capasity; PEF (L/s)- Peak Expiratory Flow; FEF25-75\% (L/s)Forced Expiratory Flow at 25-75\%; VC (L)- Vital Capacity; MVV (L/min)- Maximal Voluntary Ventilation

\section{Discussion}

The results of our study in which the effects of smoking addiction and physical activity on some respiratory functions in female students were examined are discussed respectively below.

$\mathrm{VC}$ value shows the amount of gas let out with maximal expiration following maximal inspiration [10]. FVC value decreases when there is blockage or contraction in airways [11]. In our study, differences were found in VC and FVC values of groups only in terms of the variable of physical activity. In a study in which the effects of different training methods on respiratory functions of adult women were examined, FVC and VC values of athletes were found to be significantly better when compared with sedentary individuals [12]. It can be said that FVC and VC values in female students were influenced by the variable of doing sports rather than the variable of smoking.

FEV1 value generally gives information about the state of large airways, PEF values shows the function of large airways. $\mathrm{FEF}(25-75)$ value gives information about airflow in medium and small-sized bronchi $[13,14]$. In our study, a significant difference was found in FEV1, PEF, FEF(25-75) values in favor of the groups doing physical activity and not smoking in terms of the states of both smoking addiction and doing physical activity $(\mathrm{p}<0,05)$. In a previously conducted study, it was reported that PEF and FEF $(25 \%-75 \%)$ values of women who were doing sport were significantly higher than those of sedentary women and there were no statistically significant differences in FEV1 values [13]. In another study, a statistically significant increase was found in the PEF value following running training [15]. In a study conducted on female judokas, no statistically significant difference was found between groups in terms of FEV1, PEF, FEF (25-75) values [16]. In some studies, it has been reported that smoking addiction causes contraction of large and middle airways and that this contraction was directly proportional to the duration of smoking [17]. We believe that the results of our study are due to the positive effects of physical activity such as increasing the elasticity of respiratory muscles, lung capacity and lungs and decreasing the airway resistance and also due to the common effect caused by the increase in airway resistance because of smoking.

Statistically significant difference was found in FEV1/ FVC values between athlete group and non-smoking group and non-smoking and sedentary group $(p<0,05)$. In a study conducted on university students, FEV1/FVC values of students who were smokers were found to be lower [18]. We think that this is a combined effect of the positive effect of physical activity on FEV1 value and the negative effect of smoking addiction on FEV1 value.

MVV value decreases in situations when airway resistance increases, respiratory muscles are influenced and lung and thoracic compliance increase and decrease and respiratory control mechanisms are disrupted $[19,20]$. In our study, it was found that MVV values of smoking addict sedentary female students were statistically significantly lower when compared with the other groups $(\mathrm{p}<0,05)$. In some studies, it has been reported that smoking individuals produce more phlegm 
(11). We believe that this may be due to the combined effect of physical activity and smoking addiction on the lungs.

\section{Conclusion}

Our study results show that the respiratory functions of female students who do sports are better than sedentary female students and that respiratory functions of non-smoking sedentary female students are better when compared with smoking addict sedentary female students. Thus, it can be seen clearly that physical activity improves respiratory functions, while smoking addiction clearly disrupts respiratory functions. In this context, it can be said that both factors have a significant effect on respiratory functions.

References

1. Bilici MF, Turker A. Investigation of The Effects of Smoking Addiction and Physical Activity on Some Respiratory Functions in Young Adult Males. Journal of Education and Training Studies, 2019; 7(12): 41-46. https://doi.org/10.11114/jets.v7i12.4585

2. Trinder PM, Croft PR, Lewis M. Social class, smoking and the severity of respiratory symptoms in the general population. Journal of Epidemiology and Community Health, 2000; 54: 340- 343. https://doi.org/10.1136/jech.54.5.340

3. Juusela M, Pallasaho P, Rönmark E, Seppo S, Anssi S, Bo L. Dose-dependent association of smoking and bronchial hyperresponsiveness. Eur Respir J, 2013;42:1503-12. https://doi.org/10.1183/09031936.00073712

4. Alpay B, Altuğ K, Hazar S. Evaluation of some respiratory and circulatory parameters of 11-13 students in primary school teams by comparing with non-sports students. Mehmet Akif Ersoy Üniversitesi Eğitim Fakültesi Dergisi, 2007; 8(17): 22-29. (In Turkish)

5. Leith DE, Bradley M. Ventilatory muscle strength and endurance training. $J$ Appl Physiol, 1976; 41:508-516. https://doi.org/10.1152/jappl.1976.41.4.508

6. Shin YS, Yang SM, Kim JH, Jeong UL, Mee-Young K, LimKyu L et al. Respiratory function of the Korean elite judo athletes and non-athletes. Arch Budo, 2017; 13: 297-307.

7. Caspersen CJ, Powell KE, Christenson GM. Physical activity, exercise, and physical fitness: definitions and distinctions for health-related research. Public Health Rep, 1985;100:126131.

8. Özdal M, Bostanci Ö, Dağlioğlu Ö, Ağaoğlu SA, Kabadayi M. Effect of respiratory warm-up on anaerobic power. Journal Of Physical Therapy Science,2016; 28(7): 2097-2098. https://doi.org/10.1589/jpts.28.2097

9. Tartibain B, Birami M. Acute ventilatory responses to intensive aerobic exercise in healthy young boys aged 1316 years: Relationship to anthropometric factor. Physical Activity \& Physiology Journal, 2010;4: 297-304.

10.Ergen E. Exercise Physiology. Nobel Publication Ltd. Şti, Ankara; 2002. (In Turkish)
As conclusion, due to the fact that smoking addiction and exercise had separately distinct effects on respiratory functions in female university students, we believe that sports and physical activity are not enough to prevent the damage that occurs in respiratory functions due to smoking.

\section{Support}

This study has been supported by the Department of Scientific Research Projects, MuşAlparslan University.

\section{Conflict of interest}

The authors do not have any conflict of interest.

11.Eschenbacher WL. Defining airflow obstruction. Chronic Obstr Pulm Dis (Miami), 2016; 3(2):515-518. https://doi.org/10.15326/jcopdf.3.2.2015.0166

12.Khosravi M, Tayebi SM, Safari H. Single and Concurrent Effects of Endurance and Resistance Training on Pulmonary Function. Iran J Basic Med Sci, 2013; 16: 628-34.

13.Nikhade NS, Sharma P. A Study Of Pulmonary Function Test In Workers Of Sugar Factory, Pravaranagar. Maharashtra Int $J$ Med Res Health Sci, 2012;2(1):52-58.

14. Yamak D, Yamak B. Interpretation of Pulmonary Function Tests A Practical Guide. Ankara; 2018.

15. Nourry C, Deruelle F, Guinhouya C, Baquet G, Fabre C, Bart $\mathrm{F}$, et al. High-intensity intermittent running training improves pulmonary function and alters exercise breathing pattern in children. Eur J Appl Physiol. 2005, 94:415-423. https://doi.org/10.1007/s00421-005-1341-4

16.Ermiş E, Yılmaz AK, Mayda H, Ermiş A. Analysis of respiratory function and muscle strength of elite judo athletes and sedentary females. Journal of Human Sport and Exercise, 2019;14(3): 705-710. https://doi.org/10.14198/jhse.2019.143.20

17.Boskabaday MH, Mahmoodinia M, Boskabady M, Heydari GR. Pulmonary function tests and respiratory symptoms among smokers in the city of mashhad (north east of Iran). Rev Port Pneumol, 2011;17(5): 199-204. https://doi.org/10.1016/j.rppneu.2011.05.001.

18.Dugral E, Balkanc1 D. Effects of smoking and physical exercise on respiratory function test results in students of the university. Medicine,2019;98:32. https://doi.org/10.1097/MD.0000000000016596

19.Neder JA, Andreoni S, Lerario MC, Nery LE. Reference values for lung function tests. II. Maximal respiratory pressures and voluntary ventilation. Braz $J$ Med Biol Res, 1999; 32(6):719-727.

20.Günay M, Tamer K, Cicioğlu İ. Sport Physiology and Performance Measurement. Ankara: Gazi Kitabevi; 2005. (In Turkish) 


\section{Information about the authors:}

Bilici M.F.; https://orcid.org/0000-0003-1028-0504; fatihbilic@hotmail.com; School of Physical Education and Sports, Muş AlparslanUniversity; Merkez/Muş, Turkey;

Genç A.; (Corresponding Author); http://orcid.org/0000-0003-2498-7092; aycagenc@bartin.edu.tr; Faculty of Sport Science, Bartin University; Bartin, Turkey.

Cite this article as:

Bilici MF, Genç A. The effects of smoking addiction and physical activity on some respiratory functions in female university students. Pedagogy of physical culture and sports, 2020;24(2):54-58.

https://doi.org/10.15561/26649837.2020.0201

This is an Open Access article distributed under the terms of the Creative Commons Attribution License, which permits unrestricted use, distribution, and reproduction in any medium, provided the original work is properly cited (http://creativecommons.org/licenses/by/4.0/deed.en).

Received: 03.11.2019

Accepted: 24.11.2019; Published: 30.12.2019 